\title{
Nelfinavir and non-nucleoside reverse transcriptase inhibitor-based salvage regimens in heavily HIV pretreated patients
}

\author{
Jean-Guy Baril $M D^{1}$, Eric A Lefebvre $M D^{2}$, Richard G Lalonde MD FRCPC ${ }^{3}$, \\ Stephen D Shafran MD FRCPC ${ }^{4}$, Brian Conway MD FRCPC ${ }^{5}$
}

J-G Baril, EA Lefebvre, RG Lalonde, SD Shafran, B Conway. Nelfinavir and non-nucleoside reverse transcriptase inhibitorbased salvage regimens in heavily HIV pretreated patients. Can J Infect Dis 2003;14(4):201-205.

OBJECTIVE: To assess the efficacy of nelfinavir mesylate (NFV) in combination with delavirdine mesylate (DLV) or efavirenz (EFV) and other antiretroviral agents following virological failure on other protease inhibitor (PI)-based regimens.

DESIGN: Multicentre, retrospective chart review.

METHODS: One hundred-one patients who were naive to both NFV and non-nucleoside reverse transcriptase inhibitors (NNRTIs) and who initiated NFV plus DLV or EFV-based salvage regimens were reviewed. Response to treatment was defined as a reduction in HIV ribonucleic acid (RNA) levels to unquantifiable levels (less than 50 copies $/ \mathrm{mL}$, less than 400 copies $/ \mathrm{mL}$, less than 500 copies $/ \mathrm{mL}$ ) on at least one occasion after the initiation of salvage therapy. Baseline correlates of response, including prior duration of HIV infection, prior number of regimens, viral load and CD4 cell counts were also evaluated.

RESULTS: Patients had a mean duration of HIV infection of 10 years, a mean duration of prior therapy of four years, a median of four prior nucleoside reverse transcriptase inhibitors and a median of two prior PIs. At the time of review the mean duration of salvage therapy was 63.4 weeks. Virological suppression was achieved in $59(58.4 \%)$ patients within a mean of eight weeks and maintained for a mean of 44.9 weeks (the mean follow-up was 78 weeks). Of the nonresponders, $16(38 \%)$ achieved a less than $1 \log _{10}$ decrease in HIV RNA levels. Although there was no association between baseline correlates, response rate $(75.7 \%)$ was significantly higher in patients with HIV RNA levels of 50,000 copies/mL or lower and CD4 counts greater than 200 cells $/ \mathrm{mm}^{3}$.

CONCLUSION: NFV/NNRTI-based highly active antiretroviral therapy regimens are an effective therapy in many patients who have experienced virological breakthroughs on at least one prior PI-based regimen.

Key words: Antiretroviral therapy; Nelfinavir; Non-nucleoside reverse transcriptase inhibitors; Salvage therapy
Traitement de rattrapage à base de nelfinavir et d'un inhibiteur non nucléosidique de la transcriptase inverse chez des patients porteurs du VIH déjà lourdement traités

OBJECTIF : Évaluer l'efficacité du mésylate de nelfinavir en association avec le mésylate de delavirdine, l'éfavirenz ou d'autres antirétroviraux à la suite de l'échec virologique de traitements antérieurs à un inhibiteur de protéase (IP).

TYPE D'ÉTUDE : Revue rétrospective, multicentre, de dossiers médicaux.

MÉTHODE : Nous avons passé en revue les dossiers de 101 patients jamais traités au nelfivanir et à un inhibiteur non nucléosidique de la transcriptase inverse (INNTI), qui ont reçu du nelfinavir en association avec de la delavirdine ou de l'éfavirenz à titre de traitement de rattrapage. La réaction au traitement a été définie comme une diminution du taux d'acide ribonucléique (ARN) du VIH à des valeurs indétectables (inférieures à 50 copies $/ \mathrm{ml}, 400$ copies $/ \mathrm{ml}$ et 500 copies $/ \mathrm{ml}$ ) au moins une fois après l'amorce du traitement de rattrapage. Ont également été évalués les corrélats de base de la réaction, notamment la durée de l'infection à VIH, le nombre antérieur de traitements, la charge virale et la numération des lymphocytes T-CD4.

RÉSULTATS : Voici quelques caractéristiques : durée moyenne de l'infection à VIH : 10 ans; durée moyenne des traitements antérieurs : 4 ans; nombre médian de traitements antérieurs à un inhibiteur nucléosidique de la transcriptase inverse : 4; nombre médian de traitements à un IP : 2. Au moment de l'examen des dossiers, la durée moyenne du traitement de rattrapage était de 63,4 semaines. Il y a eu suppression virologique chez 59 patients $(58,4 \%)$ en l'espace de huit semaines en moyenne et pour une durée moyenne de 44,9 semaines (durée moyenne du suivi : 78 semaines). Parmi les patients non répondeurs, $16(38 \%)$ ont connu une diminution inférieure à $1 \log _{10}$ du taux d'ARN du VIH. Même s'il n'y avait pas d'association entre les corrélats de départ, le pourcentage de réaction $(75,7 \%)$ était sensiblement plus élevé chez les patients ayant un taux d'ARN du VIH égal ou inférieur à 50000 copies/ml et un nombre de lymphocytes T-CD4 supérieur à $200 / \mathrm{mm}^{3}$.

CONCLUSION : Les traitements antirétroviraux fortement actifs à base de nelfinavir et d'un INNTI s'avèrent efficaces chez bon nombre de patients qui ont connu un rebond virologique pendant au moins un traitement antérieur à un IP.

${ }^{1}$ Clinique Médicale du Quartier Latin, Montreal, Quebec ${ }^{2}$ Clinique Médicale L'Actuel, Montreal; ${ }^{3}$ Royal Victoria Hospital, Montreal; ${ }^{4}$ University of Alberta Hospital, Edmonton, Alberta; ${ }^{5}$ University of British Columbia, Vancouver, British Columbia

Presented in part at the 41st Annual Interscience Conference on Antimicrobial Agents and Chemotherapy, Chicago, Illinois, December 2001

Correspondence and reprints: Dr Jean-Guy Baril, Clinique Médicale du Quartier Latin, 905 Boulevard René-Lévesque Est, Montreal, Quebec

H2L 5B1. Telephone 514-285-5500, fax 514-285-2226, e-mail jgbaril@videotron.ca

Received for publication December 4, 2002. Accepted May 14, 2003 
A lthough the use of highly active antiretroviral therapy (HAART) (including protease inhibitors [PIs]) has had a significant impact in decreasing HIV-related morbidity and mortality (1), virological failure of PI-based regimens is fairly common in clinical practice (2). Several predictors of virological success have been identified, including low baseline plasma viral load (VL) and high baseline CD4 cell count (2$5)$. In addition, once therapy is initiated, adherence to the regimen $(2,6,7)$ and the rate of the initial virological response (8) appear to be quite important to the long-term success of the regimen. Following confirmed virological breakthrough, current guidelines recommend using at least two new drugs in the new regimen, preferably agents to which the patient has not been previously exposed or developed resistance $(9,10)$. Although response rates of up to $90 \%$ have been reported to initial HAART, these rates decrease significantly with each subsequent treatment regimen. Thus, the design of successful second and third line HAART regimens is more challenging.

Nelfinavir mesylate (NFV) is one of several currently available HIV PIs. Although it has been shown to be effective in naive patients (11-13), its role in subsequent therapy is not clearly defined. A limited number of studies have investigated the efficacy of NFV-based regimens in patients experiencing virological breakthroughs on other PI-based regimens (14-18).

Successful salvage therapy after PI failure may depend on the incorporation of a drug from a class to which the patient is naive, as shown with the use of the non-nucleoside reverse transcriptase inhibitors (NNRTI) delavirdine mesylate (DLV) (15) and efavirenz (EFV) (19). Medications in this class have been shown to be potent agents in reducing VL (20-22). Thus, in appropriate patients the combination of NFV with an NNRTI may form the basis of a salvage regimen following virological failure on one or more PI-based regimens.

Although pharmacokinetic interactions occur when NFV is combined with $\operatorname{DLV}(23,24)$ or EFV $(25)$, no dose adjustments are recommended by the manufacturers or by current HIV guidelines (9) when these agents are used concomitantly.

The present study was undertaken to determine the efficacy of NFV used in combination with DLV or EFV and other antiretroviral agents in patients naive to the non-nucleoside class experiencing virological failure on other PI-based regimens .

\section{METHODS}

A multicentre retrospective chart review of HIV-infected adult patients was conducted at five clinics across Canada (representing over 6000 HIV patients) to identify patients who had initiated therapy including NFV and DLV, or NFV and EFV between January, 1998 and November, 2000. Patients were included in the study if they had experienced virological breakthrough on one or more previous PI-containing regimen and had been naive to NNRTIs and NFV before starting their current salvage regimen. Past regimen failure was defined as failure reported in the chart by the treating physician or as documented outcome HIV ribonucleic acid (RNA) levels greater than the limit of detection while receiving a non-NFV PI-based regimen. One hundred-one $(\mathrm{n}=101)$ patients met the inclusion criteria and were included in the study.

A chart review was performed to collect patient demographic information, antiretroviral medication history and details of the current NFV/DLV- or NFV/EFV-based salvage regimen. During the time that the patient was on this therapy, information on clin-
TABLE 1

Baseline demographics of study participants prior to the initiation of the salvage regimen

\begin{tabular}{lc}
\hline Total number of patients ( $\mathrm{n}$ ) & 101 \\
Male (\%) & $91(90.1)$ \\
Female (\%) & $10(9.9)$ \\
Race & \\
Caucasian (\%) & $97(96)$ \\
African American (\%) & $3(3)$ \\
Hispanic (\%) & $1(1)$ \\
Mean duration of HIV, years (range) & $9.8(3.1-21.1)$ \\
Mean duration of AIDS ( $\mathrm{n}=58$ ), years (range) & $5.1(0.6-10.6)$ \\
Median HIV RNA level at baseline (range) & \\
copies/mL & $31,050(598-1,369,000)$ \\
log ${ }_{10}$ copies/mL & $4.49(2.78-6.14)$ \\
Median CD4 count (cells/mm ${ }^{3}$ ) at baseline (range) & $200(3-760)$ \\
Previous anti-HIV therapies & \\
Median number of ARV agents (range) & $6(3-9)$ \\
Median number of HAART regimens (range) & $2(1-7)$ \\
Median number of PI regimens (range) & $3(1-7)$ \\
Median number of PIs (range) & $2(1-3)$ \\
Median number of NRTIs (range) & $4(1-5)$ \\
Duration of previous anti-HIV therapies & \\
Mean duration of ARV therapy (months) & 47.8 \\
Mean duration of HAART therapy (months) & 21.9 \\
\hline
\end{tabular}

ARV Antiretroviral; HAART Highly active antiretroviral therapy; NRTIs Nucleoside reverse transcriptase inhibitors; PI Proteases inhibitors; RNA ribonucleic acid

ical events, drug tolerability, HIV RNA levels (VL) and CD4 cell counts was recorded.

For HIV RNA levels, three clinics ( $\mathrm{n}=90$ patients) used the Quantiplex HIV RNA branched chain (bDNA) assay (Chiron Diagnostics, USA), with a limit of quantification of 500 copies $/ \mathrm{mL}$ before May, 1999, and 50 copies $/ \mathrm{mL}$ thereafter. Two clinics ( $n=11$ patients) used the Amplicor HIV-1 Monitor assay (Roche Diagnostics, Laval) with a limit of quantification of 400 copies $/ \mathrm{mL}$ before June, 2000, and 50 copies $/ \mathrm{mL}$ thereafter.

Virological suppression or response was defined as a reduction in plasma HIV RNA levels to unquantifiable levels (less than 50 copies $/ \mathrm{mL}$, less than 400 copies $/ \mathrm{mL}$, less than 500 copies $/ \mathrm{mL}$, depending on the clinical assay in use at the time of evaluation) on at least one occasion after the initiation of NFV/DLV- or NFV/EFV-based therapy. The response rate was stratified according to baseline HIV RNA levels (above or below 50,000

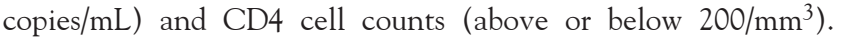
Additional endpoints that were examined included the duration of virological response and the ability to achieve a reduction in plasma VL of $90 \%\left(1.0 \log _{10}\right.$ copies $\left./ \mathrm{mL}\right)$ or greater while on therapy. Baseline correlates of response, including prior duration of documented HIV infection and prior number of treatment regimens, as well as the reasons to discontinue NFV-based therapy were also evaluated. The time period for the analysis was from the initiation of NFV/DLV - or NFV/EFV-based therapy until there was any change in the antiretroviral regimen, including changes in the nucleoside reverse transcriptase inhibitor (NRTI) backbone. Virological response was analyzed at four, 12, 24, 36 and 48 weeks after initiation of the NFV/NNRTI-based salvage regimen. For this analysis, four patients who initiated the salvage regimen less than one year before review and were still continuing the 


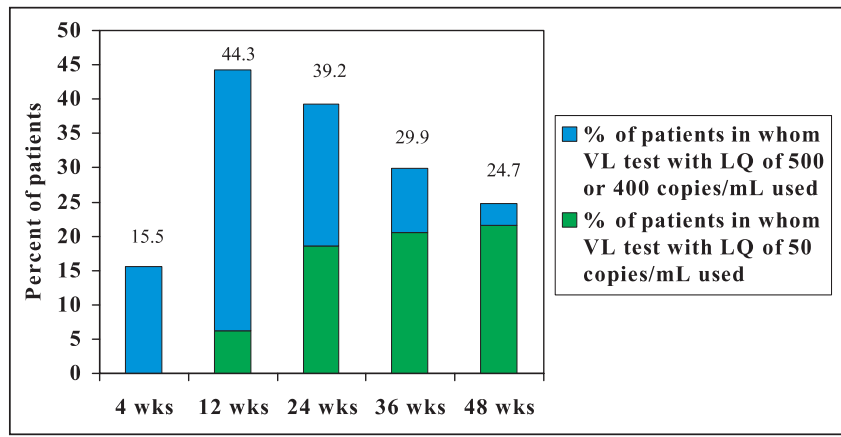

Figure 1) Patients who achieve or maintain viral suppression at timepoints after initiating NFV/DLV- or NFV/EFV-based therapy. Only patients who initiated NFV/NNRTI-based therapy at least one year before the review date were included $(n=97)$. Patients who continued the NFV/NNRTI-based regimen but had changes in other agents due to side effects while virologically suppressed were also included. DLV delavirdine mesylate; EFV Efavirenz; LQ Limit of quatification; NFV Nelfinavir mesylate; NNRTI non-nucleoside reverse transcriptase inhibitor; VL Viral load; wks Weeks

NFV/NNRTI-based regimen were excluded because they would not yet have reached some of the time points of the analysis.

\section{Statistical analysis}

Fisher's exact test was used to determine statistical significance between groups stratified according to baseline HIV RNA levels and CD4 cell counts. Trends for differences between groups were analyzed using the $\chi^{2}$ test. The significance of differences between the median values for responders and nonresponders for demographic variables (number of ARV agents, numbers of PIs, duration of documented HIV infection, baseline HIV RNA levels, log of baseline HIV RNA levels and CD4 count) was tested using the Mann-Whitney U test with SPSS for Windows (SPSS Inc, USA). A $5 \%$ limit was used as the cutoff for significance.

\section{Baseline demographics}

\section{RESULTS}

A total of 101 patients met the eligibility criteria and were included in the analysis. Of these, 81 (80\%) received EFV as their NNRTI and 20 (20\%) received DLV. Baseline demographic characteristics of study participants before the initiation of the current salvage regimen are summarized in Table 1. Most patients were white men infected with HIV for a mean of 10 years who had been receiving antiretroviral treatment for a mean of four years and HAART for a mean of 22 months. Approximately half of the patients (58 of 101, 57\%) had a prior diagnosis of AIDS for a mean duration of five years. On average, most patients had moderately advanced immune disease (median CD4 count of 200 cells $/ \mathrm{mm}^{3}$ ), half with HIV RNA levels above 30,000 copies/mL. Most patients were heavily pretreated, having received between three and nine different agents, including two separate HAART regimens. Patients had tried a median of two PIs with $82 \%$ having tried indinavir sulfate, $82 \%$ having tried saquinavir and $62 \%$ having tried ritonavir.

Effects on HIV RNA levels and CD4 cell counts At the time of data collection, all patients had received NFV/DLV- or NFV/EFV-based therapy for a mean of 63.4 weeks.
TABLE 2

Predictors of virological response

\begin{tabular}{|c|c|c|c|}
\hline & $\begin{array}{c}\text { Responders* } \\
(n=59)\end{array}$ & $\begin{array}{l}\text { Non- } \\
\text { responders } \\
(n=42)\end{array}$ & $\begin{array}{c}\text { P value } \\
\text { (Mann- } \\
\text { Whitney } \\
\text { U test) }\end{array}$ \\
\hline Median number of ARV agents tried & 6 & 6 & 0.1663 \\
\hline Median number of Pls tried & 2 & 2 & 0.2348 \\
\hline $\begin{array}{l}\text { Median duration of documented } \\
\text { HIV Infection (months) }\end{array}$ & 9.1 & 9.8 & 0.8877 \\
\hline $\begin{array}{l}\text { Median baseline plasma HIV } \\
\text { RNA levels (copies } / \mathrm{mL} \text { ) }\end{array}$ & 18,720 & 49,453 & 0.0710 \\
\hline $\begin{array}{l}\text { Median baseline plasma HIV } \\
\text { RNA levels ( } \log _{10} \text { copies } / \mathrm{mL} \text { ) }\end{array}$ & 4.27 & 4.69 & 0.0699 \\
\hline $\begin{array}{l}\text { Median baseline CD4 count } \\
\quad\left(\text { cells } / \mathrm{mm}^{3}\right)\end{array}$ & 219 & 148 & 0.0668 \\
\hline
\end{tabular}

*Virological response is defined as achieving undetectable HIV ribonucleic acid (RNA) levels on at least one occasion following the initiation of NFV/EFVor NFVIDLV-based salvage therapy. ARV Antiretroviral; DLV Delavirdine mesylate; EFV Efavirenz; NFV Nelfinavir mesylate; PI Protease inhibitor

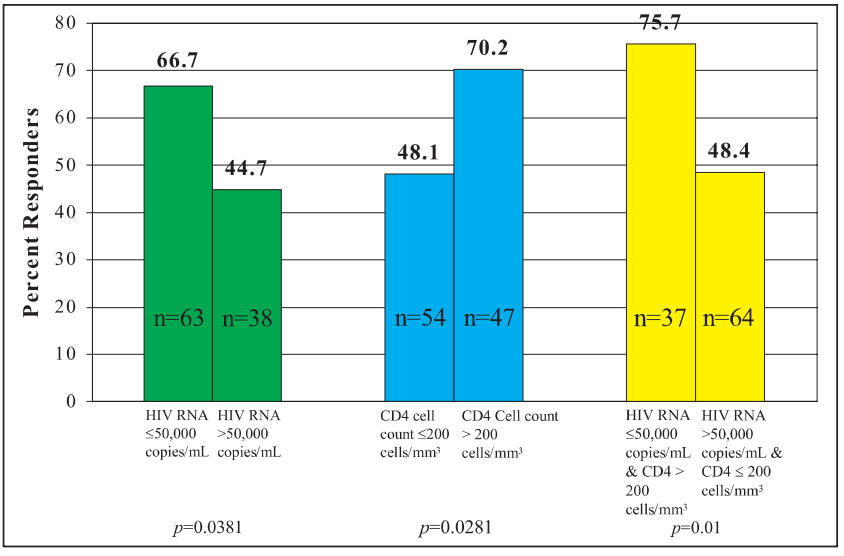

Figure 2) Response according to baseline HIV ribonucleic acid (RNA) level and CD4 cell count

Virological suppression was achieved on at least one occasion in $59(58.4 \%)$ patients (the mean follow-up was 78 weeks). At the time of first VL suppression, the standard sensitive test with a limit of quantification of 500 copies $/ \mathrm{mL}$ or 400 copies $/ \mathrm{mL}$ was being used in $44(43.6 \%)$ patients and the ultrasensitive test with a limit of quantification of 50 copies $/ \mathrm{mL}$ was being used in $15(14.9 \%)$ patients to measure HIV RNA levels. At the time of data collection, the median HIV RNA levels in responders compared to baseline had decreased from $4.27 \log _{10}$ copies $/ \mathrm{mL}$ to $2.78 \log _{10}$ copies $/ \mathrm{mL}$ and the median CD4 cell count had increased from 219 cells $/ \mathrm{mm}^{3}$ to 263 cells $/ \mathrm{mm}^{3}$. The mean follow-up in $42(41.6 \%)$ patients who did not achieve undetectable HIV RNA levels (ie, nonresponders) was 43 weeks. In the $42(41.6 \%)$ patients who did not experience virological suppression at any time (ie, who did not achieve undetectable HIV RNA levels), 16 (38\%) still showed a 90\% (1.0 $\log _{10}$ ) decrease in HIV RNA levels, with an overall increase in median CD4 cell count in these 42 individuals from 148 cells $/ \mathrm{mm}^{3}$ to 181 cells $/ \mathrm{mm}^{3}$. 
TABLE 3

Patient disposition at time of analysis

\begin{tabular}{lcc}
\hline & $\begin{array}{c}\text { No. of Patients } \\
(\mathbf{n}=101)\end{array}$ & $\%$ \\
\hline Continuing the same NFV+NNRTI-based regimen & 25 & $24.80 \%$ \\
Changes in ARV agents other than NFV+NNRTI & 25 & $24.80 \%$ \\
Due to virological rebound ${ }^{*}$ & 7 & $6.90 \%$ \\
Due to clinical deterioration $^{\prime}$ & 2 & $1.98 \%$ \\
Due to side effect ${ }^{\dagger}$ & 11 & $10.90 \%$ \\
Due to patient preference & 4 & $3.96 \%$ \\
Due to physician preference & 1 & $0.99 \%$ \\
Discontinued NFV or EFV or DLV & 46 & $45.50 \%$ \\
Due to virological rebound & \\
Due to clinical deterioration & 23 & $22.80 \%$ \\
Due to side effect & \\
Due to patient preference & 6 & $5.90 \%$ \\
Due to other or unknown reason & 10 & $9.90 \%$ \\
Lost to follow-up & 5 & $4.90 \%$ \\
\hline
\end{tabular}

${ }^{*}$ As determined by physician; 'Due to neuropathy $(n=3)$, diarrhea $(n=1)$, lipodystrophy $(n=1)$ or not documented/unknown causes $(n=6)$; $\neq$ Due to diarlipodystrophy $(n=1)$ or not documented/unknown causes $(n=6) ;+$ Due to diar-
rhea $(n=4)$, neuropsychiatric effects $(n=2)$, anemia $(n=1)$, glucose intolerance $(n=1)$, pancreatitis $(n=1)$ or not documented/unknown causes $(n=1)$. ARV Antiretroviral; DLV Delavirdine mesylate; EFV Efavirenz, NFV Nelfavir mesylate; NNRTI Non-nucleoside reverse transcriptase inhibitor

\section{Duration of response}

On average, suppression was achieved in eight (range: 1 to 30) weeks, and maintained for 44.9 (range 1.3 to 145.3 ) weeks. At 48 weeks, when the ultrasensitive test with a limit of quantification of 50 copies $/ \mathrm{mL}$ was being used in the majority of individuals, $24(24.7 \%)$ patients remained virologically suppressed (Figure 1).

Predictors of virological response/suppression

As shown in Table 2, there was no association between median duration of documented HIV infection, prior antiretroviral therapy, baseline HIV RNA levels or CD4 cell counts. A multiple regression analysis indicated that the combination of HIV RNA levels and CD4 cell counts was also not predictive of response $(\mathrm{P}=0.0847)$. However, stratification by baseline HIV RNA levels and CD4 cell counts showed a statistically significant difference in response for those patients with values above or below 50,000 copies/mL (66.7\% response versus $44.7 \%$ response, $\mathrm{P}=0.0381$ ) and above or below 200 cells $/ \mathrm{mm}^{3}$ ( $70.2 \%$ response versus $48.1 \%$ response, $\mathrm{P}=0.0280$ ) (Figure 2 ). In combining these two parameters, the best response rate (75.7\%) was seen in patients with baseline HIV RNA measures of 50,000 copies $/ \mathrm{mL}$ or lower and CD4 cell counts above 200 cells $/ \mathrm{mm}^{3}$. In contrast, only $48.4 \%$ of patients who started therapy with higher HIV RNA levels and lower CD4 cell counts achieved virological suppression $(\mathrm{P}=0.01$, Figure 2$)$.

\section{Patient disposition}

At the time of evaluation, $24.8 \%$ of patients remained on their initial regimen (Table 3). In an additional $24.8 \%$ of patients, only the NRTI backbone had been modified. Thus, $50 \%$ of patients remained on the same NFV/NNRTI combination. Overall, 30\% required a change in therapy (either NFV, NNRTI, or NRTI) due to virological breakthrough, while 20\% experienced significant toxicity, most often diarrhea, neuropathy, or neuropsychiatric symptoms (Table 3 ). Only $5 \%$ of patients were lost to follow-up.

\section{Response to DLV versus EFV}

Of the 101 patients included in the present study, 81 (80\%) received EFV and 20 (20\%) received DLV as their NNRTI. Given the limited number of patients on DLV $(n=20)$ versus $\operatorname{EFV}(n=81)$, it is difficult to interpret the role of a specific NNRTI on response during the salvage therapy.

\section{DISCUSSION}

Virological failure with PI-based regimens is common in clinical practice and the response to second-line or salvage therapy is often unsatisfactory due to the presence of resistance mutations that frequently confer cross-resistance to other members of the same drug class. Most current guidelines would favour the use of triple-class regimens in this setting, selecting an NNRTI and new PIs/NRTIs chosen to minimize the potential for cross-resistance with agents to which the individual patient may already have been exposed. The selection of specific agents may be better informed by the use of drug resistance testing.

In this context, our retrospective analysis shows that in many patients who have experienced a virological breakthrough while on one or more prior PI-based regimens, NFV plus NNRTI-based HAART regimens can be effective salvage treatment options. Although this was a retrospective study our results are similar to those reported in other randomized and non-randomized salvage studies with NFV and EFV or DLV conducted in NNRTI- and NFV-naive patients who have been heavily pretreated with PI/NRTI regimens (14-18). Hammer et al (17) report that treatment with a background of NFV/EFV/adefovir dipivoxil and either abacavir sulfate or NRTIs resulted in virological suppression (VL of less than 500 copies $/ \mathrm{mL}$ ) in $45 \%$ of patients at 16 weeks (17). In the AIDS Clinical Trials Group Study 359 (15), virological suppression (VL of less than 500 copies/mL) was achieved in $47 \%$ and $36 \%$ of patients randomized to NFV/DLV/saquinavir or $\mathrm{NFV/DLV/saquinavir/adefovir,} \mathrm{respectively} \mathrm{after} 16$ weeks. The regimens consisting of NFV/EFV with either stavudine or didanosine/hydroxyurea led to virologic suppression in $41 \%$ to $46 \%$ of patients over 24 weeks, results similar to those presented in this report $(14,18)$. The durability of virologic suppression that we have observed ( $25 \%$ over 48 weeks) is also similar to that obtained by Cassado et al (26) at 52 weeks with NFV and the NNRTI nevirapine.

Major causes of antiretroviral therapy treatment failure that have been identified include advanced stage of HIV disease, development of viral resistance during prior therapy, and insufficient drug exposure due to poor adherence, inadequate drug absorption, and unfavourable pharmacokinetics (9). In our retrospective analysis, the only factor that seemed to be associated with the inability to achieve virological suppression was more advanced immune suppression and a higher plasma VL. This confirms the observation that success of the regimen can be enhanced by making a change in therapy as soon as a true virological breakthrough is confirmed, minimizing the evolution of drug resistance to NRTIs and PIs that may be occurring and maximizing the potential benefit of introducing NNRTIs as a new drug class in salvage therapy. It may be that the use 
of resistance-testing (to allow for a more insightful selection of NRTIs and PIs) could have improved the results. Unfortunately, in the setting of this retrospective analysis, this tool was not yet available for use in our centres when the salvage regimen was being selected.

In summary, our data indicate that NFV/NNRTI-based HAART regimens offer effective therapy in many patients who have experienced a virological breakthrough on at least one prior PI-based regimen. The efficacy of this approach could be enhanced by its use in patients with early virological breakthrough, with the regimen optimized by the use of drug resistance testing and drug level monitoring. Comparison of different

\section{REFERENCES}

1. Palella FJ Jr, Delaney KM, Moorman AC, et al. Declining morbidity and mortality among patients with advanced human immunodeficiency virus infection. N Engl J Med 1998;338:853-60.

2. Lucas GM, Chaisson RE, Moore RD. Highly active antiretroviral therapy in a large urban clinic: Risk factors for virologic failure and adverse drug reactions. Ann Intern Med 1999;131:81-7.

3. Raboud JM, Montaner JSG, Conway B, et al. Suppression of plasma viral load below 20 copies $/ \mathrm{ml}$ is required to achieve a long-term response to therapy. AIDS 1998;12:1619-24.

4. Deeks SG, Hecht FM, Swanson M, et al. HIV RNA and CD4 cell count response to protease inhibitor therapy in an urban AIDS clinic: Response to both initial and salvage therapy. AIDS 1999;13:F35-43.

5. Ledergerber B, Egger M, Opravil M, et al. Clinical progression and virologic failure on highly active antiretroviral therapy in HIV-1 patients: A prospective cohort study. Swiss HIV Cohort Study. Lancet 1999;353:863-8.

6. Paterson DL, Swindells S, Mohr J, et al. Adherence to protease inhibitor therapy and outcomes in patients with HIV infection. Ann Intern Med 2000;133:21-30.

7. Montaner JS, Reiss P, Cooper D, et al. A randomized, double blind trial comparing combinations of nevirapine, didanosine, and zidovudine for HIV-infected patients. The INCAS Trial. Italy, The Netherlands, Canada and Australia Study. JAMA 1998;279:930-7.

8. Powderly WG, Saag MS, Chapman S, Yu G, Quart B, Clendeninn NJ. Predictors of optimal virological response to potent antiretroviral therapy. AIDS 1999;13:1873-80.

9. Department of Health and Human Services (DHHS) and the Henry J. Kaiser Family Foundation. Guidelines for the Use of Antiretroviral Agents in HIV-Infected Adults and Adolescents. February, 2002. $<$ www.hopkins-aids.edu/guidelines/adult/gl_adult.pdf $>$ (Version current at June 9, 2003).

10. Yeni PG, Hammer S, Carpenter CCJ, et al. Antiretroviral treatment for adult HIV infection in 2002. Updated recommendations of the International AIDS Society — USA Panel. JAMA 2002;288:222-35.

11. Henry K, Lamarca A, Myers R, Chapman S. The safety of Viracept ${ }^{\circledR}$ (nelfinavir mesylate, NFV) in pivotal phase II/III double blind, randomized controlled trials as monotherapy and in combination with either $\mathrm{d} 4 \mathrm{~T}$ or AZT/3TC. 4th Conference on Retroviruses and Opportunistic Infections. Washington, June 22-26, 1997. (Abst 384)

12. Clendennin N, Quart B, Anderson R, Knowles M, Chang Y. Analysis of long-term virologic data from the VIRACEPT (nelfinavir mesylate, NFV) 511 protocol using 3 HIV-RNA assays. 5th Conference on Retroviruses and Opportunistic Infections. Chicago, February 1-5, 1998. (Abst 372)

13. Clumeck N. AVANTI 3: A randomized, double blind comparative trial to evaluate the efficacy, safety and tolerance of AZT/3TC vs. AZT/3TC/nelfinavir in anti-retroviral naïve patients. 5 th Conference on Retroviruses and Opportunistic Infections. Chicago, February 1-5, 1998. (Abst 8)

14. Seminari E, Maggiolo F, Villani P, et al. Efavirenz, nelfinavir, and stavudine rescue combination therapy in HIV-1-positive patients heavily pretreated with nucleoside analogues and protease inhibitors. J Acquir Immune Defic Syndr 1999;22:453-60.

15. Gulick RM, Hu XJ, Fiscus SA, et al. Randomized study of saquinavir
NNRTI-based regimens in prospective studies is definitely warranted to help establish if one regimen is systematically better than others in specific patient populations. Nonetheless, our data suggest that NFV is useful in patients who have already experienced virological breakthrough on one or more prior PIbased regimens.

ACKNOWLEDGEMENT: This study was supported in part by Agouron Pharmaceuticals Inc, a Pfizer Company.

with ritonavir or nelfinavir together with delavirdine, adefovir, or both in human immunodeficiency virus-infected adults with virologic failure on indinavir: AIDS Clinical Trials Group Study 359 J Infect Dis 2000;182:1375-84.

16. Hammer S, Mellors J, Vaida F, et al. Randomized, placebo-controlled trial of saquinavir (SQV) sgc, indinavir (IDV) or nelfinavir (NFV) in combination with amprenavir (APV), abacavir (ABC), efavirenz (EFZ) and adefovir (ADV) in patients (pts) with protease inhibitor (PI) failure. 7th Conference on Retroviruses and Opportunistic Infections. San Francisco, January 30-February 2, 2000. (Abst LB7)

17. Hammer S, Squires K, Degruttola V, et al. Randomized trial of abacavir (ABC) \& nelfinavir (NFV) in combination with efavirenz (EFV) and adefovir dipivoxil (ADV) as salvage therapy in patients with virologic failure receiving indinavir (IDV). 6th Conference on Retroviruses and Opportunistic Infections. Chicago, January 31 February 4, 1999. (Abst 490)

18. Arrizabalaga J, Iribarren JA, Rodriguez-Arrondo FJ, Von Wichmann MA. Salvage therapy with ddI + hydroxyurea (HU) + efavirenz (EFV) + nelfinavir (NFV) in patients who had previously failed indinavir (IDV)/ritonavir (RIT) regimens: 24 Weeks followup. 39th Interscience Conference on Antimicrobial Agents and Chemotherapy. San Francisco, September 26-29, 1999. (Abst 2206)

19. Danner S, Brun S, Sylte J, et al. Kaletra (lopinavir/ritonavir) and efavirenz: 72 Week safety/efficacy evaluation and phenotypic/genotypic breakpoints in multiple PI experienced patients. 41st Interscience Conference on Antimicrobial Agents and Chemotherapy. Chicago, December 16-19, 2001. (Abst I-1925)

20. Moyle $G$. The emerging roles of non-nucleoside reverse transcriptase inhibitors in antiretroviral therapy. Drugs 2001;61:19-26.

21. De Clerq E. The role of non-nucleoside reverse transcriptase inhibitors (NNRTIs) in therapy of HIV-1 infection. Antiviral Res 1998;38:153-79.

22. Deeks SG, Hellmann NS, Grant RM, et al. Novel four-drug salvage treatment regimens after failure of a human immunodeficiency virus type 1 protease inhibitor - containing regimen: Antiviral activity and correlation of baseline phenotypic drug susceptibility with virologic outcome. J Infect Dis 1999;179:1375-81.

23. National AIDS Treatment Advocacy Project NNRTI - Nonnucleoside reverse transcriptase inhibitor section. NATAP reports 1998;1:5. <www.natap.org/1998/98reports/natap_reports3.5.htm> (Version current at June 9, 2003)

24. Cox SR, Schneck DW, Herman BD, et al. Delavirdine (DLV) and nelfinavir (NFV): A pharmacokinetic (PK) drug-drug interaction study in healthy adult volunteers. 5th Conference on Retroviruses and Opportunistic Infections. Chicago, February 1-5, 1998. (Abst 345)

25. Fiske WD, Bendek IH, White SJ, Pepperess KA, Joseph JL, Kornhauser DM. Pharmacokinetic interaction between efavirenz (EFV) and nelfinavir (NFV) in healthy volunteers. 5th Conference on Retroviruses and Opportunistic Infections. Chicago, February 1-5, 1998. (Abst 349)

26. Casado JL, Dronda F, Hertogs K, et al. Efficacy, tolerance, and pharmacokinetics of the combination of stavudine, nevirapine nelfinavir and saquinavir as salvage regimen after ritonavir or indinavir failure. AIDS Res Hum Retroviruses 2001;17:93-8. 


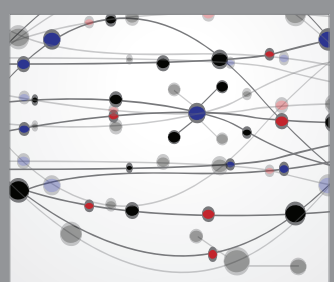

The Scientific World Journal
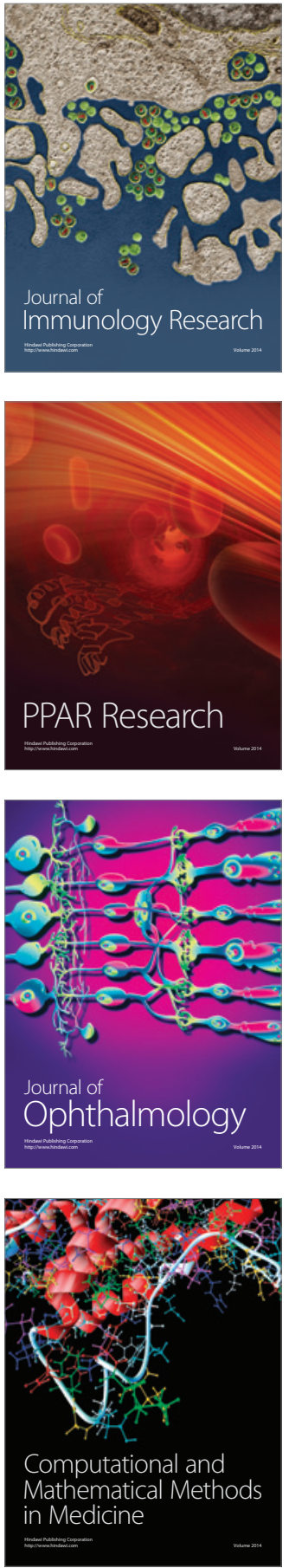

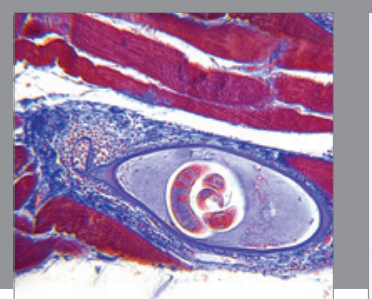

Gastroenterology Research and Practice

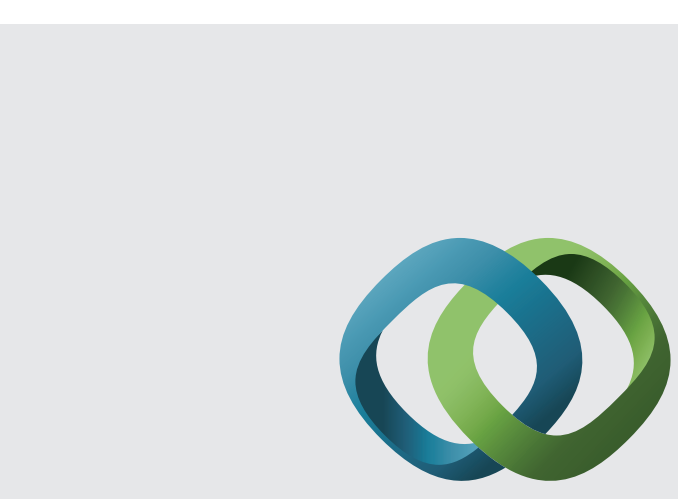

\section{Hindawi}

Submit your manuscripts at

http://www.hindawi.com
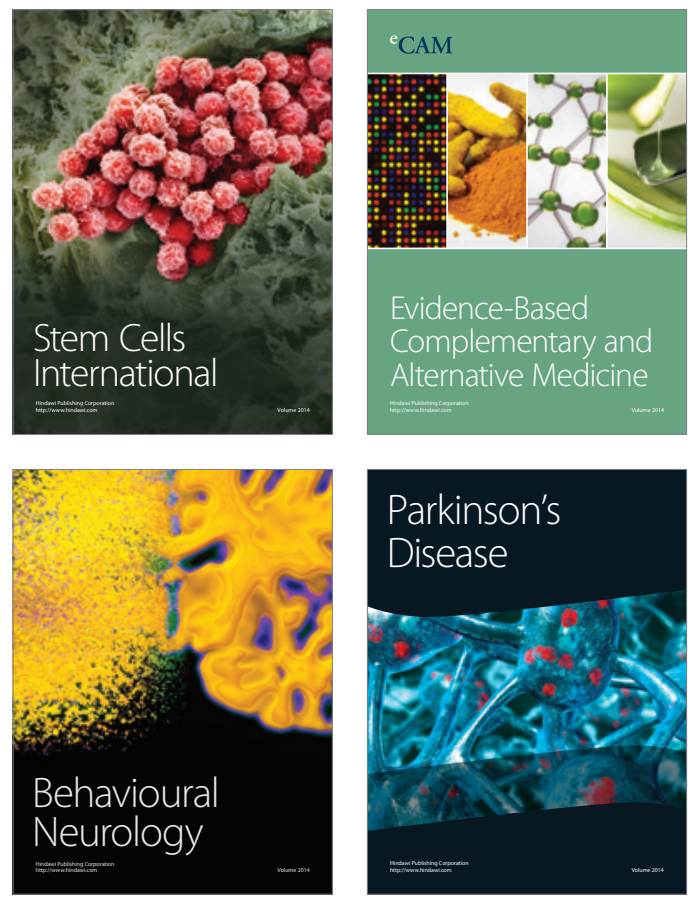
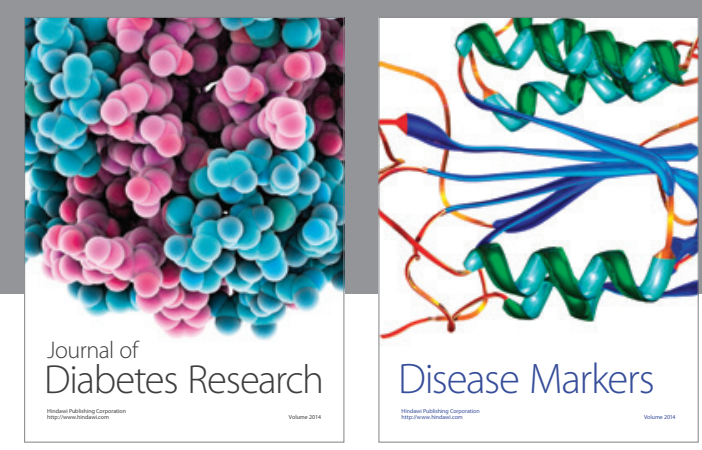

Disease Markers
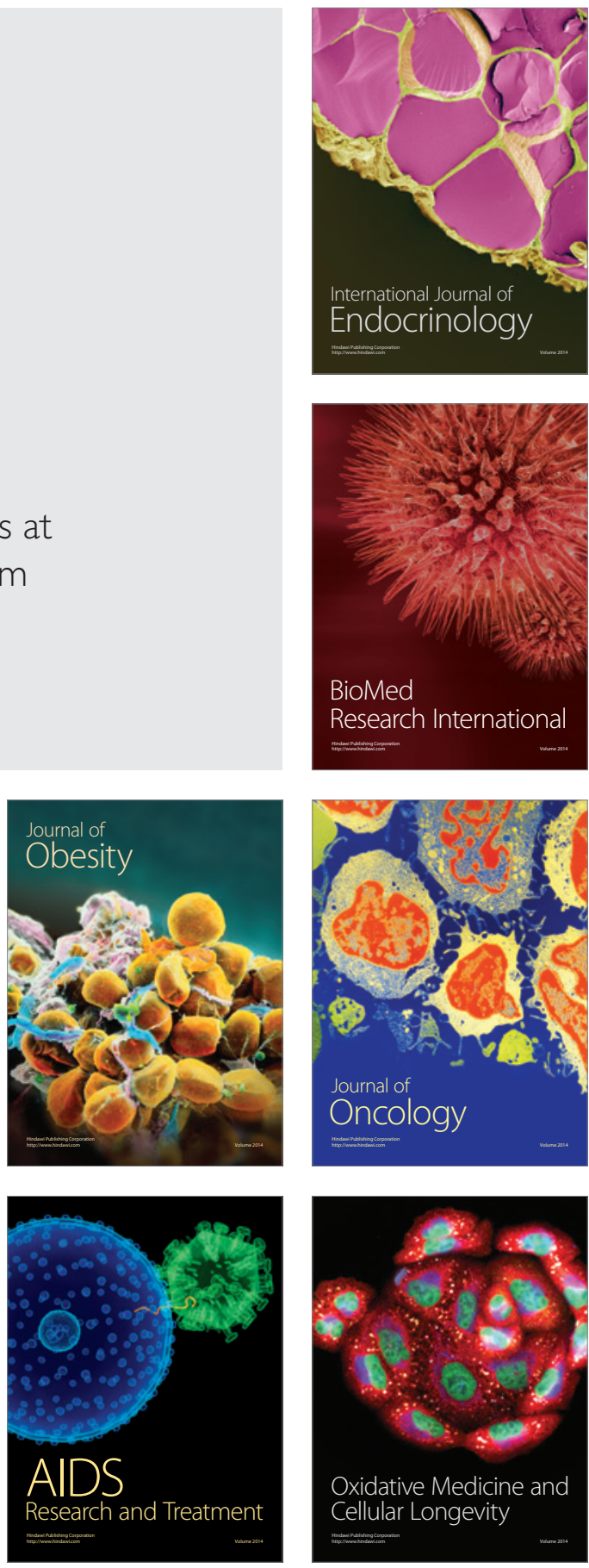